\title{
Viajeros y burócratas en la historia de la exploración territorial de la República de Chile
}

\author{
Andrés Estefane ${ }^{1}$
}

El objetivo de este texto es compartir algunas reflexiones sobre el papel de los viajeros en la historia de la exploración territorial de Chile durante los siglos XIX y XX. Su excusa es un hito bibliográfico, la Biblioteca Fundamentos de la Construcción de Chile, formada por cien trabajos pioneros en la historia científica chilena recientemente reeditados por su notable contribución al conocimiento de la realidad social y material del país ${ }^{2}$. Junto con graficar el espesor de la producción científica y académica local desde los inicios de la república hasta mediados del siglo XX (espesor no siempre reconocido en los balances intelectuales), los títulos aquí reunidos reflejan la pluralidad de enfoques y preguntas con las que se ha pensado Chile en el marco de distintos proyectos de desarrollo, situando a la geografía y la discusión jurídica, a la ingeniería y el ensayo social en un horizonte político que actualiza y refuerza la dimensión civil de todo saber ${ }^{3}$.

En lo que sigue se revisan algunos títulos de la colección que remiten a la historia de los viajes y que pueden entregar luces respecto al impacto de

1 Chileno. Doctor (c) en Historia. Investigador del Centro de Estudios de Historia Política, Universidad Adolfo Ibáñez, Chile. E-mail: andres.estefane@uai.cl. El presente texto es una versión anotada de mi intervención en el coloquio "Los libros que construyeron Chile, 18501950. Biblioteca Fundamentos de la Construcción de Chile", realizado en Santiago el 8 de septiembre de 2014 en el Salón Fundadores OTIC de la Cámara Chilena de la Construcción. Agradezco a Mariel Rubio por la invitación a dicho encuentro y a Sebastián Hernández por sus comentarios a una versión preliminar de este escrito.

2 Esta iniciativa, desarrollada en conjunto por la Biblioteca Nacional de Chile, la Pontificia Universidad Católica de Chile y la Cámara Chilena de la Construcción, se desarrolló entre los años 2007 y 2013. En ese período se editaron mil ejemplares de cada título -cien mis libros en total- que fueron enviados a las principales bibliotecas públicas del país y el extranjero. Cada volumen cuenta con una introducción en la que un especialista explica las condiciones de aparición de la obra y su importancia para el desarrollo de la ciencia y la técnica, clarificando de ese modo su inclusión en el catálogo. El proyecto supuso también la habilitación de un sitio web donde, junto a la versión digital de cada volumen, se pueden consultar textos, noticias y piezas audiovisuales para el uso de esta biblioteca como recurso pedagógico.

3 Aunque esta colección ha sido correctamente definida como una "biblioteca científica", en ella también encuentran lugar textos clásicos del ensayo social chileno, como El porvenir del hombre (1858) de Pedro Félix Vicuña, Los derechos civiles de la mujer (1898) de Matilde Brandau, Sinceridad. Chile íntimo (1910) de Alejandro Venegas, El problema nacional (1917) de Darío Salas y la compilación Chile, país de contrastes (1906-1953) de Gabriela Mistral, entre otros. Aunque estas inclusiones no alteran la impronta científico-técnica del catálogo, sí dan cuenta del sentido civil del proyecto. 
esta práctica en la configuración de una idea de país. Se abordan aquí las principales expediciones de carácter científico, pero también las visitas administrativas y periplos personales que contribuyeron a la construcción material y simbólica de la república. Tal como muestran los textos de este catálogo y otros no incluidos en la biblioteca, los viajes resultaron fundamentales para la consolidación del Estado, la explotación de recursos naturales, el avance científico y la formación de una conciencia territorial, ecológica y energética entre los ciudadanos. Relevar ese impacto es un ejercicio ineludible en una sociedad cuyo panteón ha sido ingrato con el trabajo de científicos, burócratas y artistas que dejaron retratos invaluables del país, su gente y sus recursos.

No pretendemos entregar aquí visiones sumarias ni descripciones detalladas de cada uno de estos viajes. Nos interesa, simplemente, registrar cuatro ideas que, junto con ser útiles para una evaluación crítica del viaje y su impacto en la historia de la república, pueden estimular la lectura y el reconocimiento de una iniciativa editorial que rescata y visibiliza el patrimonio científico e intelectual del país.

\section{El problema del panteón: ventajas y riesgos de estudiar a los viajeros y exploradores de la república}

No hay novedad en afirmar que el panteón republicano local está virtualmente monopolizado por figuras del ámbito militar. Esta constatación instala un primer pilar para identificar una de las ventajas de estudiar a los viajeros: conocer su historia y sus aportes a la república permite enriquecer ese panteón no solo con nuevas caras, sino también con habilidades, filosofías y principios políticos no necesariamente vinculados al mundo de las armas. Si reconocemos que la exploración del espacio es una actividad imprescindible para dotar de sentido a una comunidad política circunscrita a un territorio, ello significa aceptar que el método, la rigurosidad y la disciplina asociados a trabajos de estas características también forman parte del patrimonio valórico e intelectual que dicha comunidad debería reconocer como constitutiva.

Esto no es nuevo y lo que hace esta Biblioteca reeditando los relatos de algunos viajeros es reorientar una tendencia. El viaje, en tanto práctica y problema, se ha instalado como tema ineludible en los relatos locales sobre la modernización del país. Por lo mismo, hoy podemos hablar de la existencia de una galería célebre donde figuran muchos viajeros -la mayoría científicos, casi todos extranjeros- cuyos trabajos habrían facilitado la inserción de este país, una ex colonia pobre y periférica, en la compleja coreografía de repúblicas modernas. No es algo menor. Estas exploraciones siempre generaron reportes, informes, estudios que desde luego circularon en Chile, pero también en el extranjero. Participando de la constitución de una red internacional de producción y circulación de conocimiento estandarizado, 
los reportes científicos de estas expediciones contribuyeron a reforzar de manera palpable la visibilidad del país y su reconocimiento en el concierto internacional. Aunque los nombres de estos expedicionarios todavía pujan por ampliar las fronteras o renovar la composición del panteón oficial, que hoy sean reconocidos como grupo es signo de avance.

Estudiar a los viajeros también abre la posibilidad de entender la historia de la república desde nuevos ángulos. Nos permite enriquecer lo político vinculándolo con la ciencia y, sobre todo, con lo territorial, algo importante en un país donde el estudio y la enseñanza de la historia se ha distanciado de su antigua relación con la geografía. Los viajeros nos ayudan a recomponer ese vínculo y en especial a resituar lo espacial como una cuestión clave para entender el fenómeno del poder. Digo esto porque los exploradores son figuras que fuerzan transiciones importantes en el imaginario territorial de un cuerpo social. Algunos piensan el territorio a partir de su fisonomía, de la historia del relieve; otros lo hacen a partir del poblamiento y el impacto del hombre en el medio. Pero todos, a fin de cuentas, nos obligan a considerar la dimensión espacial. En su minuto cumplieron la crucial tarea de volver abordable lo ignoto, habitable lo inhóspito, familiar lo desconocido, y si bien en ningún caso reemplazaron o suplieron las fuerzas de la economía o el empuje de la política, sí ofrecieron los argumentos, las imágenes y las razones que una y otra, economía y política, necesitan para ponerse en marcha.

Al decir esto, no queremos exagerar el papel de los viajeros de la era republicana oscureciendo a sus antecesores de la época colonial. Los viajes imperiales, en particular los del siglo XVIII, cumplieron funciones similares y también ataron el problema geográfico al ejercicio del poder. Pero entre ambos contextos hay distancias y parte de esa brecha se explica por la naturaleza social del conocimiento que producen. Las pesquisas coloniales no necesariamente tuvieron una vocación pública y sus resultados fueron usualmente conservados y utilizados bajo la lógica de la reserva; algo muy distinto a la obsesión por la transparencia del contexto republicano, que sometió a escrutinio el trabajo de quienes eran sostenidos por el erario común (la prensa aquí jugó un papel relevante), puso en evidencia las fortalezas y debilidades de sus pesquisas e hizo de aquel material un asunto de interés público. Aunque operaran bajo el mismo paradigma científico -resta demostrar en qué minuto se superó el formato de las relaciones topográficas coloniales- estamos ante experiencias que no pueden ser reducidas a un horizonte común.

Existen buenas razones, entonces, para estudiar a los viajeros y su aporte a la república. Pero también hay riesgos y el mayor de ellos es convertir a estos hombres en nuevos genios culturales, en representantes de virtudes -como el trabajo, la disciplina, la inteligencia- que aparentemente serían escasas en estas latitudes. Ahí reside un problema serio, pues tras esas conversiones siempre se instalan ficciones moralizantes que despistan y neutralizan los be- 
neficios de que el panteón republicano también esté integrado por científicos. Convengamos en que no es fácil evitar este riesgo, sobre todo por el atractivo de armar genealogías de exploradores que desnudan los recovecos de una república situada al fin del mundo. Hay aquí ingredientes épicos donde se cruzan la fascinación geográfica y la narrativa heroica, pero lo fundamental es resistir la tentación de aquellas miradas canónicas que exageran el carácter, la disciplina y el tesón de estos hombres de ciencia. Esto no significa desconocer sus esfuerzos ni negar la radicalidad de sus opciones, que en muchos casos los llevaron a abandonar sus patrias de origen para correr las fronteras del conocimiento en tierras nuevas, de características extremas. Se trata, simplemente, de que sean recordados como lo que fueron, científicos rigurosos, no como santos laicos.

La configuración de estas narrativas heroicas en torno a las virtudes de un individuo también nos puede llevar a olvidar que estos expedicionarios casi nunca viajaron solos y que el conocimiento que produjeron también reposó en el trabajo, a veces anónimo, realizado por otros. Es la escenificación local de una brillante frase atribuida a Fernand Braudel: "Europa ha redescubierto el mundo, muy a menudo, con los ojos, las piernas y la inteligencia de los demás". Resultó común que estos expedicionarios fueran asistidos por agentes contratados por el Estado, ayudantes que se formaban en los rigores de la investigación científica y también por quienes producían ciencia en el espacio local. Así se desprende de la historia de producción de la Geografía física de la República de Chile, publicada en 1875 por el geólogo francés Pedro José Amado Pissis, quien llegó al país en 1848 contratado por el gobierno de Manuel Bulnes mientras Claudio Gay, otro gran expedicionario, llevaba adelante su viaje de reconocimiento por el territorio chileno. El mismo Pissis reconoció sus deudas científicas en el prefacio a su obra, identificando a los pares cuyo trabajo había servido de referencia y a los ingenieros y topógrafos locales que lo habían asistido en su comisión: "[d]eseando sobre todo presentar el conjunto de los fenómenos naturales, he creído necesario consultar además las obras de los naturalistas que han recorrido el país; y más particularmente el gran trabajo del señor Claudio Gay sobre la flora y la fauna de Chile. Las publicaciones mineralógicas del señor Domeyko me han servido para completar el cuadro de las especies minerales, y para la meteorología he recurrido a menudo a las observaciones de los señores Donoso, Fonk [sic] y Schythe; finalmente debo a la oficiosidad de los señores Cuadra, Concha y Drouilly, ingenieros de la comisión topográfica, importantes observaciones sobre la geología y la meteorología"(Pissis, 2011: 3). Los registros de figuras similares -Ignacio Domeyko, Hans Steffen, Francisco Fonck, Rodulfo Philippi, Francisco Vidal Gormaz, Alberto de Agostini- replican el gesto y sostienen la regla. Ahora, conviene recordar que el apoyo no siempre fue científico o técnico, sino también militar y debido a un asunto que la autocomplaciente narrativa republicana tiende a minimizar: la ubicuidad de la violencia, sobre 
todo a campo traviesa, y que puso en riesgo no pocas de estas empresas científicas. Como simple muestra, en su contrato con Pissis el mismo gobierno se comprometió a sufragar el sueldo de un soldado que lo acompañaría en todo momento y de un escolta cuando se internara en territorios inseguros.

\section{Los otros viajeros: burócratas, artistas y simples aventureros}

Para los exploradores científicos la república es un laboratorio, un espacio de investigación y reflexión, una zona abierta al lenguaje universal de la ciencia y sus categorías. Desde esa plataforma asistieron al Estado en la tarea de enfrentar y reducir la ignorancia, uno de los grandes enemigos de todo orden en fase de constitución. Por eso mismo estas figuras son recordadas y reclaman su espacio en el panteón de la república. Pero el territorio fue también recorrido bajo otros criterios, definidos por meras necesidades administrativas e incluso por impulsos personales. Es entendible que estos otros viajeros, que podríamos llamar menores, tengan baja visibilidad, aunque sus expediciones hayan sido tan o más decisivas que las formalmente científicas. Sus viajes pertenecen a otra esfera. Son experiencias que se inscriben en la pesada rutina burocrática, las opacas tareas de fiscalización y control administrativos, la fijación de protocolos entre funcionarios civiles, el reconocimiento territorial que antecede a las medidas de gobierno.

En un libro de reciente aparición, la historiadora Elvira López reconstruyó una de esas expediciones rutinarias, la de Victorino Garrido, el primero en ejecutar las funciones de visitador fiscal en las dependencias administrativas de la república a inicios de la década de 1830 (López, 2014: 177-192). Su caso es ilustrativo de cómo una cuestión coyuntural, la organización de comisiones de visita para conocer el estado de la administración provincial, terminó siendo una situación propicia para recopilar noticias útiles al gobierno. Corresponde precisar que la "utilidad" pudo haber sido relativa, cuando no inexistente, pero se trató a la larga de experiencias relevantes para la fijación de técnicas de indagación que eventualmente podían trasplantarse a otros contextos con la migración burocrática de los agentes públicos. Junto a Garrido y después de Garrido emergen los "burócratas ambulantes" del Estado, los visitadores de escuela, los visitadores provinciales de la Oficina de Estadística, los visitadores judiciales y también los funcionarios de correos, en rigor todos aquellos que recorrieron el territorio y dieron cuenta de él con un nivel de detalle quizá superior al de los grandes exploradores (Estefane, 2012a: 3-4). Casi cuarenta años después de Garrido, otro funcionario estatal, Tulio Rengifo, recorrió todo el territorio nacional para enseñar a los burócratas de provincia algo simple, pero crucial: cómo producir estadísticas confiables y construir archivos locales para preservar esa información. Aquí 
el viaje se convierte en una empresa pedagógica que tiene la función de educar la mirada y unificar el lenguaje, preparando agentes que multipliquen la capacidad del Estado de extraer, ordenar y procesar información social de manera uniforme (Estefane, 2012b: xlv-liii).

Hoy pocos recuerdan a Garrido o a Rengifo, aun cuando sus comisiones resultaron fundamentales. ¿Por qué? Porque fueron empleados menores que gastaron sus días en comisiones itinerantes al servicio de una estructura burocrática que los puso en terreno, los convirtió en instrumento y los invisibilizó. Sus textos e informes, considerados obras mínimas, simples reverberaciones de fórmulas convencionales, cargan hoy con la mala fama que tiene todo documento oficial. Como aquí la autoría parece ser algo anecdótico, es común que estos reportes terminen confundidos con el discurso de la autoridad o la idea abstracta de poder. Sabemos, sin embargo, que el asunto tiene una textura más densa. Quien reconoce que tras cada documento oficial hay un agente con nombre y apellido, quien acepta que las fórmulas narrativas del sistema burocrático también pueden ser impredecibles, no puede eludir la pregunta por la identidad de los delegados que recorrieron el territorio recopilando datos, acumulando testimonios y redactando los informes que nutrirán el discurso y la praxis de los conductores del Estado. Parece necesario, entonces, seguir las huellas dejadas por esos burócratas ambulantes que, amparados en la cimbreante legitimidad del poder central y hurgando en las trastiendas de lo cotidiano, recorrieron y narraron a su modo aquellos espacios donde el proyecto impuesto por la elite de Santiago, hasta bien avanzada la república, tendía a desdibujarse o desaparecer.

\section{Mujeres en tránsito}

Independiente de que nos inmunicemos frente a la circulación de relatos épicos sobre la exploración territorial de la república, hay un retrato romántico (en el fondo político) del que resulta difícil escapar. Ese relato nos lleva a pensar en hombres -sí, siempre hombres- cabalgando bajo el sol inmisericorde del Valle Central, envueltos en nubes de polvo formadas al ritmo del galope, nubes que decantan en las alforjas gastadas donde el viajero acumula de todo: formularios repletos de una caligrafía endemoniada, restos de frutos secos, un par de informes sobre salubridad redactados por el médico del último pueblo, una petaca a medio llenar, padrones y cuadernos todavía en blanco, un par de referencias geográficas obtenidas de boca de un vecino y también el miedo a ser asaltado; hombres navegando en botes viejos conducidos por locales que recorren casi de memoria los canales y riachuelos del extremo sur, expuestos a lluvias inclementes que amenazan con invadir estuches de tabaco y cuadernos de notas personales que recogen los primeros balbuceos del etnógrafo moderno; hombres cargados de instrucciones, sin muchos recursos, que andan y desandan las 
rutas trazadas en un papel que parece ser un mapa, pero que de poco sirve para llegar al próximo yacimiento minero. En fin, hombres que recorren hasta el último rincón del territorio nacional cumpliendo las órdenes del Estado o tratando de servir a la ciencia, acumulando datos sueltos, pidiendo informes y compulsando testimonios para beneficio del poder que los cobija y al que representan; hombres que instalan la lógica moderna en territorios fronterizos; figuras ambulantes que a través de sus desplazamientos van construyendo la nación, el Estado, y todo lo que deba construirse para hacer real la república moderna.

Exceptuando a María Graham, no es común que pensemos en protagonismos femeninos al invocar retratos de ese tipo. Pero deberíamos, porque las mujeres viajaron mucho y en condiciones similares a sus pares. Volvemos aquí a una idea ya planteada: el desplazamiento por la república durante el siglo XIX supuso exponerse a una violencia latente. El territorio estaba plagado de riesgos y por eso el Estado hizo que sus exploradores fueran acompañados por soldados o destinara escoltas cuando se trataba de penetrar territorios problemáticos. No hay reporte sin registro de alguna forma de violencia o donde el viajero no haya dejado zonas grises, inciertas, confiadas a la imaginación geográfica, por miedo a que un asalto o un ataque animal tiraran por la borda el conocimiento y quizás la vida. Son viajeros como los de Carpentier en El siglo de las luces, esos que salían al camino esperándose lo peor.

Existen varias historias de viajes femeninos que desafortunadamente no calificaron para este catálogo. Pienso en Florence Dixie, quien recorrió la Patagonia entre 1878 y 1879, antecediendo a exploradores connotados como Steffen o De Agostini. Se dice, no lo he comprobado, que ella fue la primera en describir con pelos y señales -e instalar en el imaginario europeola majestuosidad de las Torres del Paine. Lo hizo en su libro Across Patagonia (Dixie, 1880), que llegó a manos del mismo Darwin y que sigue siendo casi desconocido en estas latitudes, o que al menos no supera en circulación a textos como el de Steffen (2010) o De Agostini (2010). Pienso también en Marianne North, otra británica que viajó a Chile, específicamente a la Araucanía, en 1884, un año después de que el ejército chileno aplastara el último levantamiento mapuche e impusiera un cierre provisional a la invasión de Arauco. North viajó por ese territorio hostil, fracturado por la ira de la derrota y la paranoia del invasor, pintando la flora chilena ${ }^{4}$.

4 Benjamín Vicuña Mackenna fue uno de los más solícitos anfitriones de North en Chile. Preso de su irreflexiva fascinación por lo extranjero, en noviembre de ese año publicó una extensa nota presentando en sociedad a tan ilustre visita. ("Una visita ilustre. Miss North", en El Mercurio de Valparaíso, 1 de noviembre de 1884). De él y aquella nota, North escribió: "Un día mi amiga Mrs. Proctor -la única dama inglesa que, exceptuando a Mrs. Pakenham, vivía en Santiago-, subió trayendo a don Benjamín Vicuña di Mackenna 
Visibilizar el protagonismo femenino es otra vía para enriquecer la galería local de exploradores, problematizando algunos de los supuestos que operan en la caracterización global del viaje. Sin embargo, se trata de un reconocimiento que no puede estar inmune a la crítica respecto a la forma en que esas experiencias dialogan con las representaciones dominantes. Es lógico que nos interesemos por aquellas viajeras cuyos registros iluminan problemas descuidados o proponen lecturas improbables, pero también debemos poner atención en aquellas que reproducen e incluso refuerzan las convenciones menos luminosas de su tiempo (Franco y Ulloa, 2014: 319). Solo de esa manera podremos entender la complejidad de la experiencia en la que se encuentran ambos tipos de relatos.

\section{La exploración de la República y la expansión territorial del país}

Uno de los aciertos de esta biblioteca es reunir viajeros y exploradores que dan cuenta de Chile en distintos momentos de su historia territorial. Las fronteras cronológicas de la colección tienden a coincidir, de hecho, con la época donde se verifica el proceso de expansión que explica el mapa actual, desplegado mediante invasiones y guerras convencionales o lentos procesos de colonización. Basta pensar que el primer expedicionario reeditado en esta colección, Claudio Gay, comenzó su viaje en un país donde la soberanía efectiva iba de Copiapó a Concepción, la población superaba con suerte al millón de habitantes y el territorio se organizaba en no más de diez provincias. Cuatro o cinco décadas más tarde, cuando se incorporan los terrenos invadidos en el ciclo liberal, la superficie del país casi se ha duplicado (incluyendo a Antofagasta y Tarapacá junto a la Araucanía e Isla de Pascua), las provincias suman casi veinte y la población bordea los dos millones y medio. Las primera mitad del siglo XX será el escenario de cierre de ese proceso, con la colonización de Aysén y la declaración de soberanía sobre Territorio Antártico.

Si estos textos pueden servir para reconstruir la expansión territorial del país, también ofrecen la posibilidad de entender algunas transiciones socio-espaciales específicas comparando narraciones generadas en mo-

(sic), un escritor y patriota muy distinguido, quien venía a verme (...) y a ver mi obra, que lo impresionó tanto que escribió un artículo largo y florido en el diario sobre mí, diciendo, entre otras cosas, que yo me internaba en países soleados, pintando el cielo azul y la luz, 'para llevarlos al pobre pueblo de Londres, que nunca ve la luz ni el cielo, iy que ni siquiera sabe cómo son!'". Generalmente bienintencionada, no será la primera vez en referirse a Vicuña con cierta compasión. Marianne North, "Diario de viaje" (Echenique y Legassa, 1999: 72 y 74). 
mentos distintos. Esa es otra manera de evaluar las transformaciones de la república. Encontramos, por ejemplo, la Araucanía descrita a mediados de la década de 1840 por el científico polaco Ignacio Domeyko (2010, $1^{\text {a }}$ ed. 1846), que guarda un aire de familia con el texto del agrimensor y político Antonio Varas, quien la visitó a fines de esa misma década (Varas, 1849). Pero ambos son retratos que anteceden a la violenta incorporación de esa zona a la economía nacional, proceso descrito por el general Cornelio Saavedra, en calidad de protagonista de la sangrienta operación, en su misma fase de desarrollo (2009, $1^{\mathrm{a}} \mathrm{ed}$. 1870). Atacama es otra frontera recurrente. Luego de permanecer desatendida por siglos, sus recursos la rehabilitaron y con el tiempo se convertirá en trampolín para otra expansión, pasando de mero despoblado a territorio de conflictos (Vicuña, 1995). En ese trance la región también tuvo sus exploradores y acumuló una maciza saga de retratos: el del incansable Rodulfo Philippi a mediados del siglo XIX (2009, $1^{\text {a }}$ ed. 1854), el de Francisco Aracena en la época de transformación (2011, $1^{a}$ ed. 1884) y el de su tocayo, Francisco San Román, quien publica su relato cuando Atacama ya no era frontera, sino un territorio de paso en un Chile nuevo que se alargaba hacia el norte (2012, $1^{\text {a }}$ ed. 1896).

Qué decir de la Patagonia, lugar que concentra fantasías, desafíos para la ciencia y más de un problema para la diplomacia de un país que, tras conocerse por dentro, debió delinear sus fronteras con ayuda de la ciencia. La creación de una Patagonia chilena es quizás el guión con que se pueden anudar los distintos reportes que cubren la zona, emparentando las exploraciones de comunicación trasandina de Guillermo Cox en la década de 1860 (2012, $1^{\text {a }}$ ed. 1863), los trabajos de Hans Steffen que desde fines del siglo XIX contribuyeron a la delimitación geográfica (2010, $1^{a}$ ed. 1909-1910) y las animadas excursiones de otro viajero incansable, Alberto de Agostini, el cura salesiano que tras dejar los pies en la montaña se atrevió a reconocer estas tierras en avioneta allá por la década de 1930 (2010, 1945). Como si fuera poco, también editó un documental, Tierras magallánicas, estrenado en 1933.

A lomo de mula y caballo, a pie, en bote o ferrocarril, e incluso en avioneta como De Agostini, estos y otros exploradores contribuyeron de manera importante a la historia de este país, narrando en clave territorial el rápido y violento proceso de expansión de una república que en el transcurso de un siglo y en catarsis traumáticas amplió sus fronteras de sur a norte, se fijó en el Pacífico (algo más tarde en el extremo polar), mientras sus arterias de carruajes, ferrocarriles y líneas telegráficas se engrosaban diariamente. De todo esto quedó registro en libros memorables, producidos en un contexto donde científicos y técnicos todavía trabajaban a favor de un proyecto de alcance nacional y donde la ciencia y el conocimiento eran insumos imprescindibles para la planificación de la república. Por el acierto de rescatar esos 
documentos, poniéndolos a disposición de nuevas generaciones políticas, es que saludamos su reedición y promovemos su lectura.

\section{Referencias bibliográficas}

\section{Publicaciones oficiales}

Varas, A. (1849). Informe presentado a la Cámara de Diputados por el Visitador Judicial de la República. Santiago: Imprenta de Julio Belin y Compañía.

\section{Artículos de libros y revistas}

Estefane, A. (2012a). "Burócratas ambulantes. Movilidad y producción de conocimiento estadístico en Chile, 1860-1873-, en Revista Enfoques, Vol. X, No 17, pp. 123-146.

Estefane, A. (2012b). "Enumerar lo que se gobierna. La producción del Anuario Estadístico de la República de Chile", en Anuario Estadístico de la República de Chile. Santiago: Cámara Chilena de la Construcción: Pontificia Universidad Católica de Chile: Biblioteca Nacional de Chile, pp. ix-|xi.

Franco, S.M.S. y Ulloa, C. (2014). "Dos viajeras latinoamericanas en la Europa del siglo XIX. Identidades nacionales y de género en perspectiva comparada: Maipina de la Barra (1834-1904) y Nisia Floresta (1810-1885), en Revista Eletrônica da ANPHLAC No. 17, p. 304-324.

\section{Libros}

Aracena, F. (2011). Apuntes de viajes. La industria del cobre en las provincias de Atacama y Coquimbo y los grandes y valiosos depósitos carboniferos de Lota y Coronel en la Provincia de Concepción. Santiago: Cámara Chilena de la Construcción: Pontificia Universidad Católica de Chile: Biblioteca Nacional de Chile (1ª edición, 1884).

Cox, G. (2012). Viaje en las regiones septentrionales de la Patagonia. Santiago: Cámara Chilena de la Construcción: Pontificia Universidad Católica de Chile: Biblioteca Nacional de Chile (1ª edición, 1863).

De Agostini, A. (2010). Andes patagónicos. Viajes de exploración a la cordillera patagónica austral, 2 vols. Santiago: Cámara Chilena de la Construcción: Pontificia Universidad Católica de Chile: Biblioteca Nacional de Chile (1ª edición, 1941, 2ª edición, 1945).

Dixie, F. (1880). Across Patagonia. London: Richard Bentley \& Son. 
Domeyko, I. (2010). La Araucanía y sus habitantes. Recuerdo de un viaje hecho en las provincias meridionales de Chile, en los meses de enero y febrero de 1845. Santiago: Cámara Chilena de la Construcción: Pontificia Universidad Católica de Chile: Biblioteca Nacional de Chile (1ª edición, 1846).

Echenique, A. y Legassa, M. (1999). La flora chilena en la mirada de Marianne North, 1884. Santiago: Pehuén Editores.

López, E. (2014). El proceso de construcción estatal en Chile. Hacienda pública y burocracia (1817-1860). Santiago: DIBAM.

Philippi, R. (2009). Viaje al desierto de Atacama. Santiago: Cámara Chilena de la Construcción: Pontificia Universidad Católica de Chile: Biblioteca Nacional de Chile (1ª edición, 1854).

Pissis, A. (2011). Geografía física de la República de Chile. Santiago: Cámara Chilena de la Construcción: Pontificia Universidad Católica de Chile: Biblioteca Nacional de Chile (1ª edición, 1875).

Saavedra, C. (2009). Documentos relativos a la Ocupación de Arauco. Santiago: Cámara Chilena de la Construcción: Pontificia Universidad Católica de Chile: Biblioteca Nacional de Chile (1ª edición, 1870).

San Román, F. (2012). Desierto y cordilleras de Atacama. Santiago: Cámara Chilena de la Construcción: Pontificia Universidad Católica de Chile: Biblioteca Nacional de Chile (1ª edición, 1896).

Steffen, H. (2010). Viaje de exploración y estudio en la Patagonia Occidental, 2 vols. Santiago: Cámara Chilena de la Construcción: Pontificia Universidad Católica de Chile: Biblioteca Nacional de Chile (1ª edición, 1909-1910).

Vicuña, M. (1995). La imagen del desierto de Atacama (XVI-XIX): del espacio de la disuasión al territorio de los desafíos. Santiago: Editorial Universidad de Santiago.

\section{Sitios web}

Biblioteca Fundamentos de la Construcción de Chile (última visita: 4 de mayo de 2015) [ http://www.bibliotecafundamentos.cl/index.php?option=com_ frontpage\&ltemid $=1$ ] 